\title{
Within-strain facilitation and disruption of avoidance learning by picrotoxin '
}

D. J. ZERBOLIO, JR. UNIVERSITY OF MISSOURI AT ST. LOUIS

Eighty 60 day old Swiss Webster mice, run 10 trials a day for four consecutive days in a wheel turn avoidance situation were divided into four groups of $20 \mathrm{Ss}$ each. All Ss were injected with either Saline, $1.0,2.0$ or $3.0 \mathrm{mg} / \mathrm{Kg}$ of Picrotoxin at the end of each day's session. Results indicate that Picrotoxin can facilitate or disrupt the acquisition of the CAR. A significant curvilinear trend for avoidance performance vs drug dose level was found indicating that low and moderate dosages produce increasing facilitation whereas high dosages produce debilitation of performance. The results are consistant with the perseveration-consolidation model of memory formation.

Many workers have shown that drugs which nonspecifically increase central nervous system (CNS) activity; e.g., strychnine sulfate and picrotoxin can facilitate learning on a wide variety of tasks (McGaugh, 1961, 1966; Petrinovich, 1963; Breen \& McGaugh, 1961; Bovet, McGaugh, \& Oliverio, 1966). Many of these studies are predicated on the perseverationconsolidation model of memory formation which hypothesizes that drugs increasing nonspecific CNS activity increase perseveration rate, and, as a consequence, increase consolidation of memory trace. But some studies have shown that drugs can have a disruptive as well as a facilitative effect on learning and memory formation (McGaugh, 1961). The disruptive effect has been attributed to too high a dose (Greenough \& McGaugh, 1965) or differences in the acetylcholine/cholinesterase ratio (Stratton \& Petrinovich, 1963). The present study shows both facilitation and disruption of a wheel turn avoidance task.

\section{Method}

Subjects. Eighty naive male Swiss-Webster mice, approximately 60 days of age, provided by the animal colony at the Department of Psychobiology of the University of California at Irvine were used.

Apparatus. Two wheel turn avoidance boxes, described in detall in Zerbolio (1967) were used throughout. The CS, a 4000 cps tone, was delivered into the wheel turn box by a Sonalert module mounted on a clear plastic lid. The US was a $1.5 \mathrm{~mA}$ constant current shock delivered to the grid floor via a four line relay grid scrambler. Each wheel turn box was housed in a sound resistant refrigerator shell appropriately modifled to allow air circulation and visual inspection of S's behavior at all times. Programming of trials and recording of S's activity was handled by appropriate timer, counter, and relay circuitry.

Procedure. All Ss were run 10 trials a day for four consecutive days. The CS was presented on a variable interval schedule, ranging from 20-60 $\mathrm{sec}$ by $10 \mathrm{sec}$ increments with a mean of 40 sec. The CS-US interval was $5 \mathrm{sec}$ and $\mathrm{S}$ could terminate CS or CS plus US by a $1 / 4$ wheel turn. If $S$ did not wheel turn (escape) within $5 \mathrm{sec}$ after the US onset, the US was terminated automatically. This procedure was adopted to prevent loss of Ss by electrocution through biting the grid. The number of avoidances, escapes, and total number of wheel turns was automatically recorded for all sessions.

The Ss were divided into a control (saline) and three drug dose groups of $20 \mathrm{Ss}$ each. Prior to each day's session, each $\mathrm{S}$ was weighed to the nearest gram. Immediately after the last trial, $S$ was removed and injected IP with $.01 \mathrm{cc} / \mathrm{g}$ of body weight of fluid containing saline only, $1.0 \mathrm{mg} / \mathrm{kg}, 2.0 \mathrm{mg} / \mathrm{kg}$, or $3.0 \mathrm{mg} /$ $\mathrm{kg}$ of picrotoxin in a saline vehicle.

\section{Results}

Since Ss were not injected until after the first day's session, the first day and the subsequent three days' data were treated separately. A one way analysis of variance (ANOVA) showed no differences between groups in avoidance rate for Day 1 (F< 1; see Fig. 2). In addition, wheel turn rate data were analyzed. All

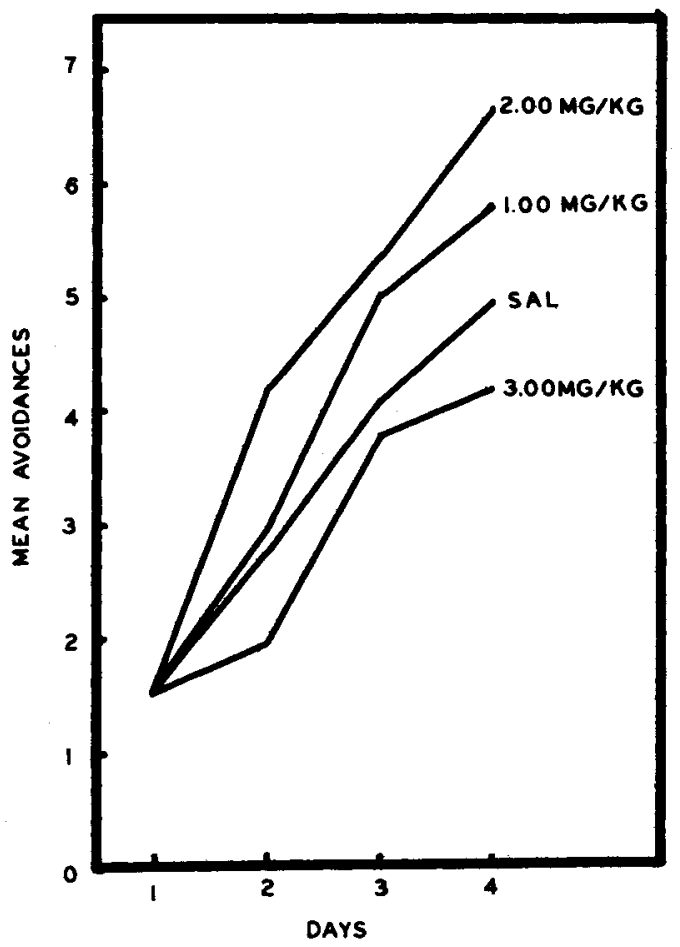

Fig. 1. The mean avoidances per daily session for the Saline control and Picrotoxin groups. All groups were statistically equivalent and are represented as a single point for Day 1. 


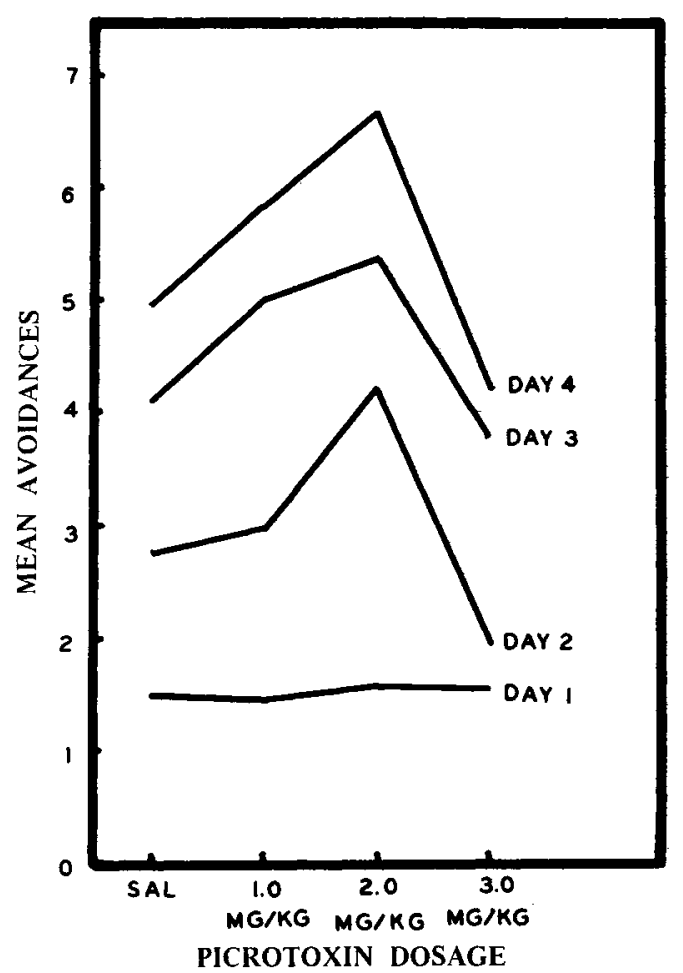

Fig. 2. The mean avoidances per drug doses for the Saline control and Picrotoxin groups. The figure indicates no differences between groups on Day 1 prior to drug injection but the significant curvilinear trend thereafter.

wheel turns were subjected to a square root transformation to reduce mean-variance correlation, and then analyzed with a one way ANOVA. No differences between groups were found $(F<1)$. Since all groups were equivalent, they were lumped and appear in Fig. 1 as a single point.

The data for Days 2-4 were analyzed for avoidance rate by days and drug dose, and appear in Fig. 1. A two way repeated measures ANOVA (Winer, 1962) indicated a highly significant training effect $(F=23.69$, df $=2 / 152, p<.01$ ) and a significant drug effect ( $F$ $=2.79, \mathrm{df}=3 / 76, \mathrm{p}<.05)$. The drug by training interaction was not significant $(F<1)$. An additional ANOVA found no significant differences in square root transformed wheel turn rates between drug groups $(F=1.82$, $\mathrm{df}=3 / 76, \mathrm{p}>.05)$, for training $(F=2.92, \mathrm{df}=2 / 152, \mathrm{p}>$ $.05)$, or their interaction $(F<1)$. In addition a trend analysis for the combined avoidance data of Days 2, 3 , and 4 was calculated (Winer, 1962). A significant quadratic component $(F=6.54, \mathrm{df}=1 / 76, \mathrm{p}<.05)$ was found and is represented in Fig. 2 as the curvilinear effect of drug dose level by avoidance rate for Days 2, 3, and 4. Linear $(F<1)$ and cubic $(F=1.65, d f=$
$1 / 76, p>.05)$ trends were not found to be statistically significant.

\section{Discussion}

The results of the present study show that IP picrotoxin injected immediately postsession can enhance or disrupt the acquisition of a wheel turn avoidance response, depending on the dosage used. Small or moderate amounts of drug facilitate and large amounts debilitate CAR acquisition. This effect is quite consistent with McGaugh's (1961) finding using strychnine sulfate. In this study, all injections were administered after daily sessions. Consequently, the facilitatory or debilitory effect of the drug is most likely on the postsession memory storage of what has been learned during the immediately preceding session. Picrotoxin can be thought to increase perseveration-consolidation rate by increasing nonspecific CNS activity. To a point, this increase apparently is beneficial but, beyond it, CNS hyperactivity produces debilitation by interfering with ongoing perseveration and consolidation of the trace. In the present study, some of the $3.0 \mathrm{mg} / \mathrm{kg}$ Ss did display seizures following injection, which would lend support to this view. But Ss showing selzures did not differ from other group members on subsequent days of testing.

In sum, the effect of picrotoxin injected postsession in mice shows a curvilinear effect on the acquisition of a wheel turn avoidance response, producing increasing facilitation of acquisition with low and moderate dosages and debllitating acquisition with high dosages.

\section{References}

BREEN, R. A., \& McGAUGH, J. L. Facilitation of maze learning with post trial injections of picrotoxin. J. comp. physiol Psychol, 1961, $54,498-501$.

BOVET, D., McGAUGH, J. L., \& OLIVERIO, A. Effects of post trial administration of drugs on avoidance learning of mice. Life Sci, $1966,5,1309-1313$.

GREENOUGH, W. T., \& McGAUGH, J. L. The effect of strychnine sulfate on learning as a function of time of administration. Psychopharmacology, 1965, 8, 290-294.

McGAUGH, J. L. Facilitative and disruptive effects of strychnine sulfate on maze learning. Psychol Rep., 1961, 8, 99-104.

PETRINOVICH, L. Facilitation of successive discrimination learning by strychnine sulfate. Psychopharmacology, 1963, 4, 103-113.

STRATTON, L. O., \& PETRINOVICH, L. Post-trial injections of an anticholinesterose drug and maze learning in two strains of rats. Psychopharmacology, 1963, 5, 47-54.

WINER, B. J. Statistical principles in experimental design, New York: MeGraw-Hill, 1962.

ZERBOLIO, D. J., JR. Differences between three inbred mouse strains on a wheel turn avoidance task. Psychon. Sci., 1967, 7, 201-202.

Note

1. This study was in part supported by USPHS Grants MH07015 and MH10261 while the author was an NIMH Post-doctoral Fellow at the Dept. of Psychobiology, University of California at Irvine. 